This item was submitted to Loughborough's Research Repository by the author.

Items in Figshare are protected by copyright, with all rights reserved, unless otherwise indicated.

\title{
Semiconductor-ionic membrane of LaSrCoFe-oxide-doped ceria solid oxide fuel cells
}

PLEASE CITE THE PUBLISHED VERSION

http://dx.doi.org/10.1016/j.electacta.2017.07.128

PUBLISHER

(C) Elsevier

VERSION

AM (Accepted Manuscript)

\section{PUBLISHER STATEMENT}

This work is made available according to the conditions of the Creative Commons Attribution-NonCommercialNoDerivatives 4.0 International (CC BY-NC-ND 4.0) licence. Full details of this licence are available at: https://creativecommons.org/licenses/by-nc-nd/4.0/

\section{LICENCE}

CC BY-NC-ND 4.0

\section{REPOSITORY RECORD}

Wang, Baoyuan, Yixiao Cai, Chen Xia, Jung-Sik Kim, Yanyan Liu, Wenjing Dong, Hao Wang, et al.. 2017. "Semiconductor-ionic Membrane of Lasrcofe-oxide-doped Ceria Solid Oxide Fuel Cells". figshare. https://hdl.handle.net/2134/26249. 


\section{Graphical Abstract}

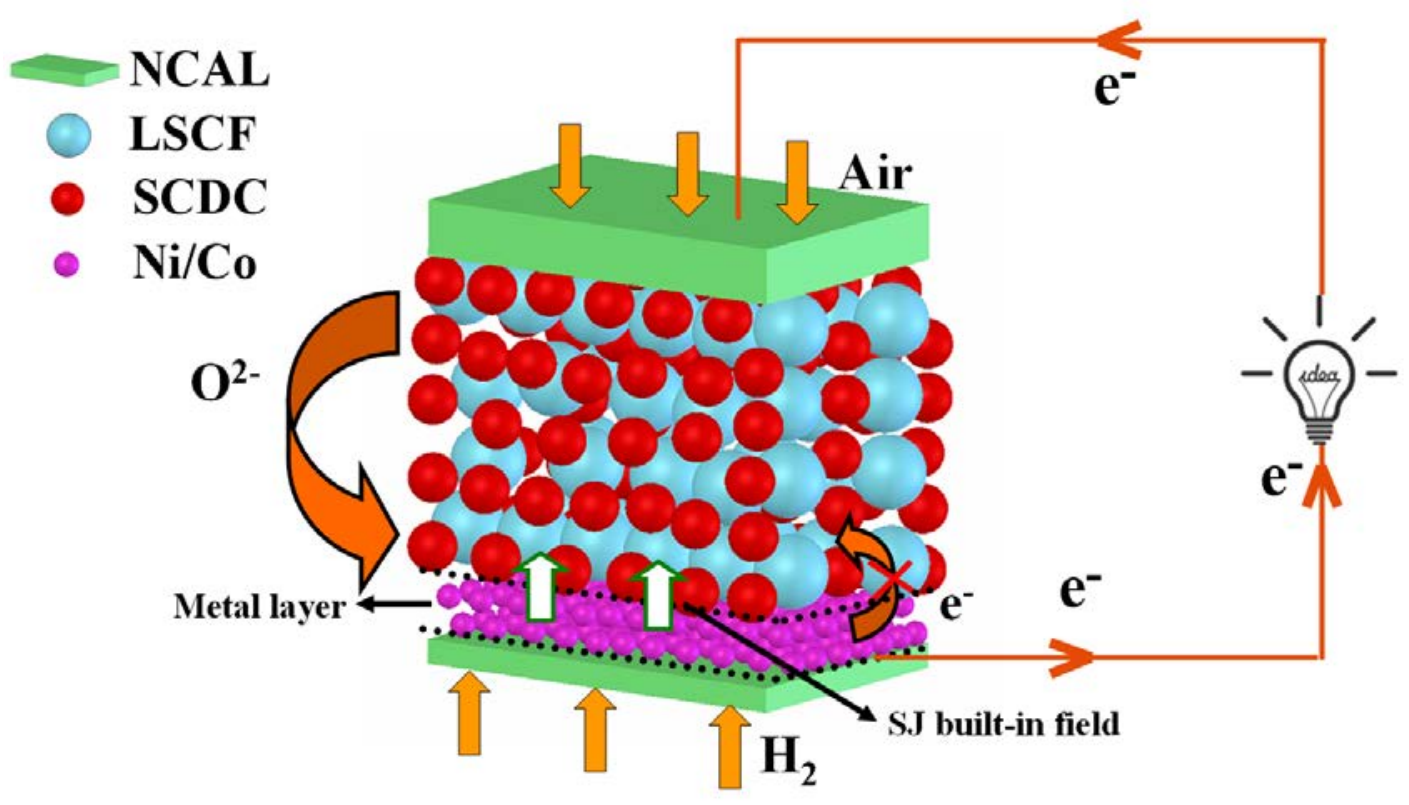

Abstract: A novel fuel cell was constructed by using semiconductor $\mathrm{La}_{0.6} \mathrm{Sr}_{0.4} \mathrm{Co}_{0.2} \mathrm{Fe}_{0.8} \mathrm{O}_{3-\delta}$ (LSCF) and ionic conductor Sm/Ca co-doped $\mathrm{CeO}_{2}$ (SCDC) nanocomposite layer as a membrane, sandwiched by two thin semiconducting layers of $\mathrm{Ni}_{0.8} \mathrm{Co}_{0.15} \mathrm{Al}_{0.05} \mathrm{Li}$-oxide (NCAL). Such device reached the output power density as high as $798 \mathrm{~mW} \mathrm{~cm}^{-2}$ at $550{ }^{\circ} \mathrm{C}$ in comparison to the fuel cell using the ionic SCDC electrolyte membrane, around $300 \mathrm{~mW} \mathrm{~cm}^{-2}$. The LSCF electronic conductor introduced into the membrane did not cause any short circuit but brought the significant enhancement on the power output. The physical semiconductor energy band alignment is proposed to prevent the internal electrons passing incorporated with the Schottky junction effect. The idea of combining semiconductor physics and ionic electrochemical FC process to employ the semiconductor-ionic membrane represents a new energy conversion technology, which is superior to the conventional fuel cell technologies. 


\section{Semiconductor-ionic Membrane of LaSrCoFe-oxide-doped Ceria Fuel Cells}

Baoyuan Wang ${ }^{1,3}$, Yixiao Cai ${ }^{2}$, Chen Xia ${ }^{1,3}$, Jung-Sik Kim ${ }^{4}$, Wenjing Dong ${ }^{1}$, Hao Wang $^{1}$, Bin $\mathrm{Zhu} \mathrm{u}^{1,3 * *}$

${ }^{1}$ Hubei Collaborative Innovation Center for Advanced Materials, Faculty of Physics and Electronic Science, Hubei University, Wuhan, Hubei 430062, P.R. China.

${ }^{2}$ Department of Engineering Sciences, Ångström Laboratory, Uppsala University, 75121

Uppsala, Sweden.

${ }^{3}$ Department of Energy Technology, Royal Institute of Technology, Stockholm, SE-10044,

Sweden.

${ }^{4}$ Department of Aero \& Auto Engineering, Loughborough University, Ashby Road, Loughborough, UK, LE11 3TU.

*Correspondence to: Prof. B. Zhu (zhubin@hubu.edu.cn; binzhu@kth.se); Prof. H. Wang (nanoguy@126.com)

Keyword: semiconductor-ionic membrane; fuel cells; co-doped ceria; ionic conductivity; 
Invented by Sir Grove in $1839^{[1]}$, fuel cells (FC) have a typical construction involving three components: anode, electrolyte, and cathode in a membrane electrode assembly (MEA) ${ }^{[2-4]}$. Among all those components, the electrolyte contributes the most significant impact ${ }^{[5]}$. As seen from the latest studies, a variety of FCs have been developed based on different types of electrolytes, such as PEMFC (polymer electrolyte membrane fuel cell) ${ }^{[6]}$, AFC (alkaline fuel cell) [7], PAFC (phosphoric acid fuel cell), MCFC (molten carbonate fuel cell) ${ }^{[8]}$, and SOFC (solid oxide fuel cell) ${ }^{[9]}$. The characteristics of electrolytes are crucial, which can determine the specific applicable fields of the respective FC technologies as well as the final system, and even in realizing the ultimate energy conversion efficiency at certain temperatures. For example, in order to utilize yttria-stabilized zirconia (YSZ) or doped ceria as the electrolyte, operating temperatures as high as $1000{ }^{\circ} \mathrm{C}$ (for YSZ) and $800{ }^{\circ} \mathrm{C}$ (for doped ceria materials) are strictly required for the SOFC to obtain a sufficiently high ionic conductivity $\left(0.1 \mathrm{~S} \mathrm{~cm}^{-1}\right)^{[10,11]}$. Historically, there has been a large limitation in selecting proper materials for the utilization of electrolyte. For already existing electrolyte materials, they suffer from high costs and high energy consumption during the operating process, thus hindering the progress for commercialization. Almost no electrolyte materials with the required conductivities can be qualified for SOFCs to operate at low temperatures $\left(<600{ }^{\circ} \mathrm{C}\right)$. In this sense, it is necessary to develop new concepts to replace those conventional electrolytes.

Recently, the electrolyte-free fuel cell (EFFC), developed by Zhu et al. ${ }^{[12,13]}$, demonstrated an effective strategy to develop the next generation of fuel cells by removing the electrolyte layer, thereby largely circumventing those limitations. The EFFC made from a homogeneous mixture layer of $\mathrm{Li}_{0.15} \mathrm{Ni}_{0.45} \mathrm{Zn}_{0.4}$ oxide and SDC (samarium-doped ceria) exhibits a high power output of 
around $600 \mathrm{~mW} \mathrm{~cm}^{-2}$ at a low temperature of $550{ }^{\circ} \mathrm{C}^{[12]}$. To progress, various types of EFFCs have been developed by using different materials from other groups, such as SrFeMo, MgZnOSDC etc. ${ }^{[14,15]}$. In the development process of EFFC, there was an issue en-regarding the device stability, due to the single homogeneous material layer had being required to form an anode zone by reacting with the supplied $\mathrm{H}_{2}$; consequently, the reduction of oxide to catalyst metal would occur. This formation of metal would persist during the EFFC operation, thus presenting with-a risk of short circuiting problem-that couldte affect the long term durability of the device. To overcome this problem, in this study,_-extra electrode layers of $\mathrm{Ni}_{0.8} \mathrm{Co}_{0.15} \mathrm{Al}_{0.05} \mathrm{Li}$-oxide (NCAL) are added at both the anode and the cathode sides in this study. The NCAL is a commercial nickel-cobalt-based oxide which can be reduced to form NiCo (Li) alloy, acting as a highly efficient anode catalyst with superior electrical properties. Moreover, the NCAL exhibits high electrical conductivity (p-type) of about $10 \mathrm{~S} \mathrm{~cm}^{-1}$, while on the cathode side, it acts as a catalyst to promote the oxygen reduction reaction (ORR). In this way, we novel device was fabricated a novel device-for fuel-to-electricity conversion, by combing the conventional FC and current EFFC technologies. The fabrication of this device is established on semiconductor $\mathrm{La}_{0.6} \mathrm{Sr}_{0.4} \mathrm{Co}_{0.2} \mathrm{Fe}_{0.8} \mathrm{O}_{3-\delta}$ (LSCF) and ionic conductor Sm/Ca co-doped $\mathrm{CeO}_{2}$ (SCDC) layer as a membrane, sandwiched by two semiconducting NCAL layers. The configuration of the device is illustrated in figure 1s (a), nominated as 'the semiconductor-ion membrane fuel cell'. The influence of Sm dopant content towards device performance was investigated, together with the effect of the composition ratio between the SCDC and LSCF.

For eomparisons-comparison, used-two FC technologies_were used: i) an identical method to construct the FC using pure ionic SCDC layer as the electrolyte membrane, in figure 1s (b); ii) 
the conventional FC method using the SCDC as the electrolyte, LSCF as the cathode and NCAL as the anode. Both anode and cathode were prepared by mixing with SCDC electrolyte at a volume ratio of $1: 1$ in order to maximize the area of triple phase boundary ${ }^{[16]}$, shown in figure $1 \mathrm{~s}$ (c). All devices after being mounted into the testing setup were examined using an in-situ preheat-treatment process at $600{ }^{\circ} \mathrm{C}$ for 1 hour then to measurements.

The SCDC was synthesized by a facile two-step process, including the first preparation of $\mathrm{Ca}^{2+}$ doped $\mathrm{CeO}_{2}$, i.e. $\mathrm{Ca}_{0.04} \mathrm{Ce}_{0.96} \mathrm{O}_{2-\mathrm{x}}(\mathrm{CDC})$ and further introducing $\mathrm{Sm}^{3+}$ into $\mathrm{CDC}$, the detailed description can be found in the experimental session. The influence of Sm dopant amount on the performance of SCDC was investigated. Components of the SCDC serial samples were identified and analyzed by the energy dispersive spectrometer (EDS). Figure 1A shows the EDS spectrum of CDC, where Ce, Ca and O were detected for the CDC sample, and the molar ratio of $\mathrm{Ca}$, $\mathrm{Ce}$ and $\mathrm{O}$ is close to 0.04:0.96:1.84, indicating the $\mathrm{CDC}$ is stoichiometric. For the SCDC samples, the presence of Ce and Ca are ascribed to CDC material, and the detected Sm signal is attributed to the incorporation of $\mathrm{Sm}\left(\mathrm{NO}_{3}\right)_{3}$ during the $2^{\text {nd }}$ step synthesized process. The EDS spectra of SCDC material with different Sm dopant content are shown in Figure 1B-F and the inset images exhibited the weight ratio. The atom ratios were calculated as shown in Table $\mathbf{1 .}$ It can be found that the molar ratios of Ca among all the samples were maintained at 0.04 , which results from the fixed composition of $\mathrm{Ca}$, and the Sm atom ratio increased with the amount of Sm( $\left(\mathrm{NO}_{3}\right)_{3}$ incorporation. All the samples can be summarized as the formula of $\mathrm{Ca}_{0.04} \mathrm{Ce}_{0.96}$ ${ }_{x} \mathrm{Sm}_{\mathrm{x}} \mathrm{O}(\mathrm{x}=0,0.05,0.09,0.16,0.24)$. 

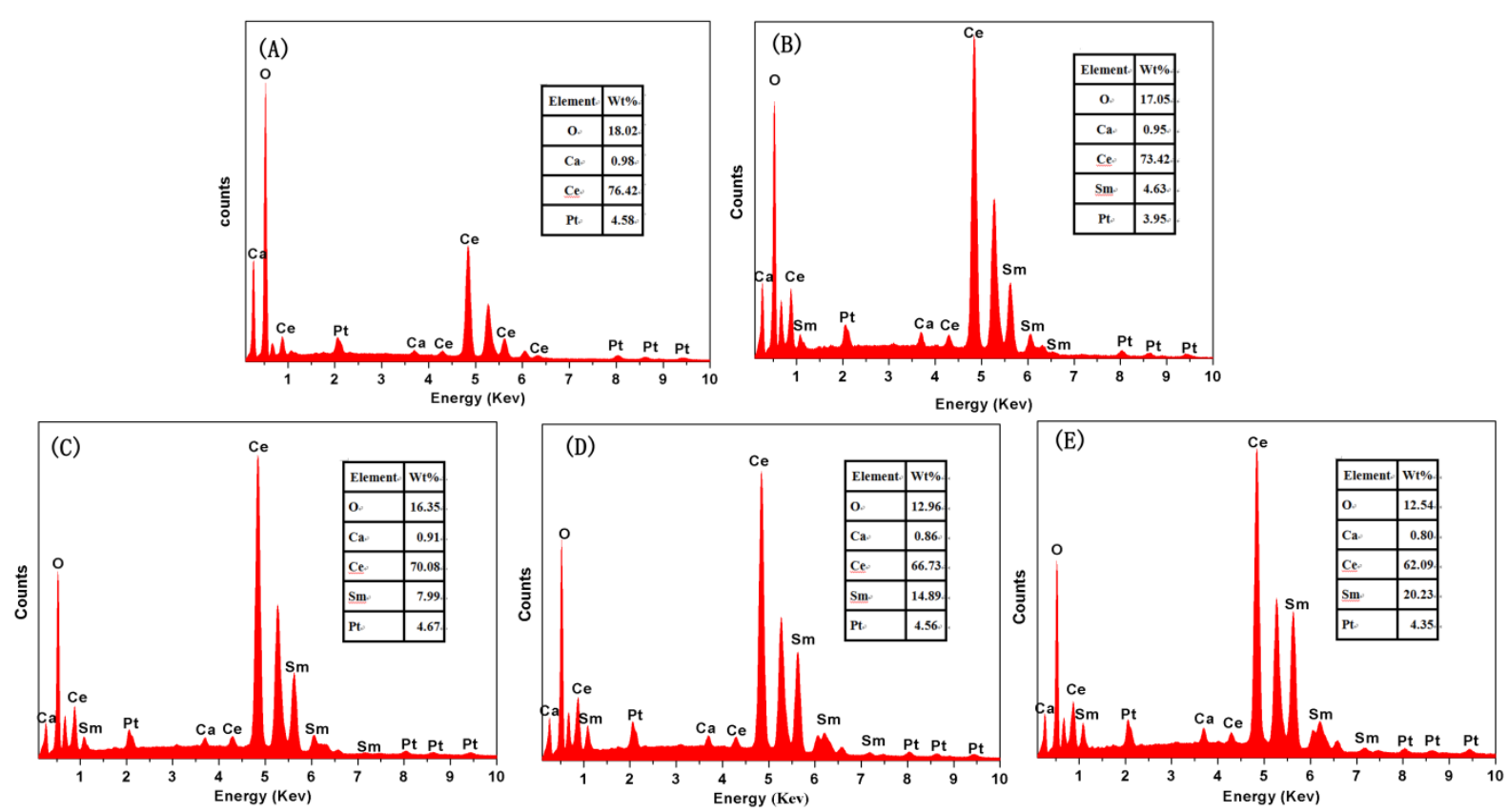

Figure 1. The EDS spectra of CDC (A) and SCDC with different contents of Sm dopant.

Table 1. The atom ratios were calculated from EDS.

\begin{tabular}{cc}
\hline Sample ID & Atom ratio \\
\hline CDC & $\mathrm{Ca}_{0.04} \mathrm{Ce}_{0.96} \mathrm{O}_{1.84}$ \\
SCDC1 & $\mathrm{Ca}_{0.04} \mathrm{Ce}_{0.91} \mathrm{Sm}_{0.05} \mathrm{O}_{1.83}$ \\
SCDC2 & $\mathrm{Ca}_{0.04} \mathrm{Ce}_{0.87} \mathrm{Sm}_{0.09} \mathrm{O}_{1.73}$ \\
SCDC3 & $\mathrm{Ca}_{0.04} \mathrm{Ce}_{0.80} \mathrm{Sm}_{0.16} \mathrm{O}_{1.30}$ \\
SCDC4 & $\mathrm{Ca}_{0.04} \mathrm{Ce}_{0.72} \mathrm{Sm}_{0.24} \mathrm{O}_{1.21}$ \\
\hline
\end{tabular}

Figure 2 shows the X-ray diffraction (XRD) patterns of the as-synthesized powder samples in the $\mathrm{Ce}_{0.96-\mathrm{x}} \mathrm{Ca}_{0.04} \mathrm{Sm}_{\mathrm{x}} \mathrm{O}_{2-\delta}$ series. The broad diffraction peaks indicate the nanocrystalline structure of the as-prepared powder. It is worth noting that all the powder samples exhibit the same diffraction patterns, where the diffraction peaks were indexed to the cubic fluorite phase of $\mathrm{CeO}_{2}$ (JCPDS 34-0394). However, for the limited sensitivity, there is no detectable phase from 
Sm clusters or Sm oxides, even though the content of Sm in the composite reaches to $23.23 \mathrm{wt} \%$. The calculated lattice constant of Ca doped $\mathrm{CeO}_{2}$ (CDC) was $5.426 \AA$, which is larger than 5.411 $\AA$ in pure $\mathrm{CeO}_{2}$. According to the elastic energy, Kim's expression implies that the critical radius (effective ionic radius) of ceria doping with divalent and trivalent metals is $0.1106 \mathrm{~nm}$ and $0.1038 \mathrm{~nm}$, respectively ${ }^{[17]}$. The radius of $\mathrm{Ca}^{2+}(0.112 \mathrm{~nm})$ is larger than the critical radius $(0.1106 \mathrm{~nm})^{[18]}$. Therefore, the lattice constant increases due to the $\mathrm{Ca}^{2+}$ doping. It can be seen clearly in an enlarged scale for $55-80^{\circ}$ as shown in Figure 2B, the peaks shift to lower 2 theta value with increasing $\mathrm{Sm}$ dopant due to the $\mathrm{Sm}^{3+}$ having larger radius $(0.1219 \mathrm{~nm})$ than the critical radius $(0.1038 \mathrm{~nm})^{[19,20]}$. These results indicate $\mathrm{Sm}$ and Ca are well doped into the crystal lattice of ceria. The XRD pattern of individual LSCF was also shown in Figure 2s (b), which is well indexed as a cubic perovskite structure and the sharp lines revealed well-developed crystallization without any detectable impurity phases. In addition, Figure 2s (c) presents the diffractogram of 50LSCF-50SCDC $(\mathrm{x}=0.16)$ composite, all the peaks can be assigned to LSCF and SCDC, no new peaks were detected, suggesting LSCF-SCDC was formed without generating any side reaction. 

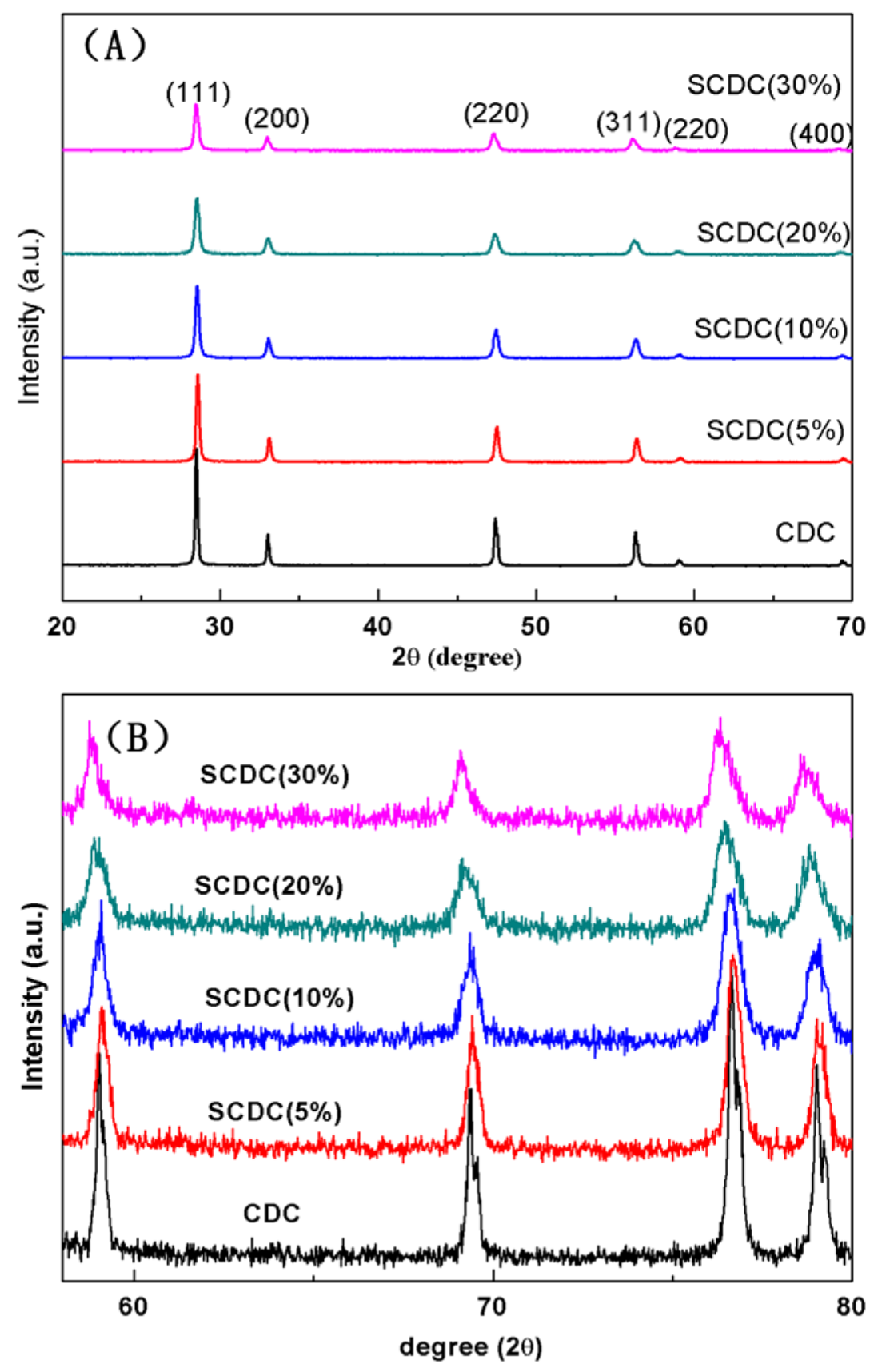

Figure 2. X-ray diffraction patterns of $\mathrm{Ce}_{0.96-\mathrm{x}} \mathrm{Ca}_{0.04} \mathrm{Sm}_{\mathrm{x}} \mathrm{O}_{2-\delta}$ series.

Figure 3 shows field emission scanning electron microscope (FESEM) images of SCDC $(\mathrm{x}=0.16)$, LSCF and LSCF-SCDC composite samples. The particle size, morphology and homogeneous distribution can been modified during the preparation, especially for the sintering temperature and reaction time. The particle size of LSCF ranges from 50-700 nm. Interestingly, the SCDC nanoparticles display uniform size distribution with an average diameter of $20 \mathrm{~nm}$, 
and the particles are faceted with occasionally irregular shape. Moreover, it can be observed from Figure 3C that the LSCF-SCDC composite consists of irregular shape particles with a wide range of size distribution, e.g. from nano-size to micro-size with some agglomeration. This is due to the use of commercial LSCF materials without elaborate control of particle size and morphology. The result from the EDS analysis (Figure 3D) for the LSCF-SCDC $(x=0.16)$ composite reveals the molar ratios of $\mathrm{La}, \mathrm{Sr}, \mathrm{Co}$, Fe component is close to
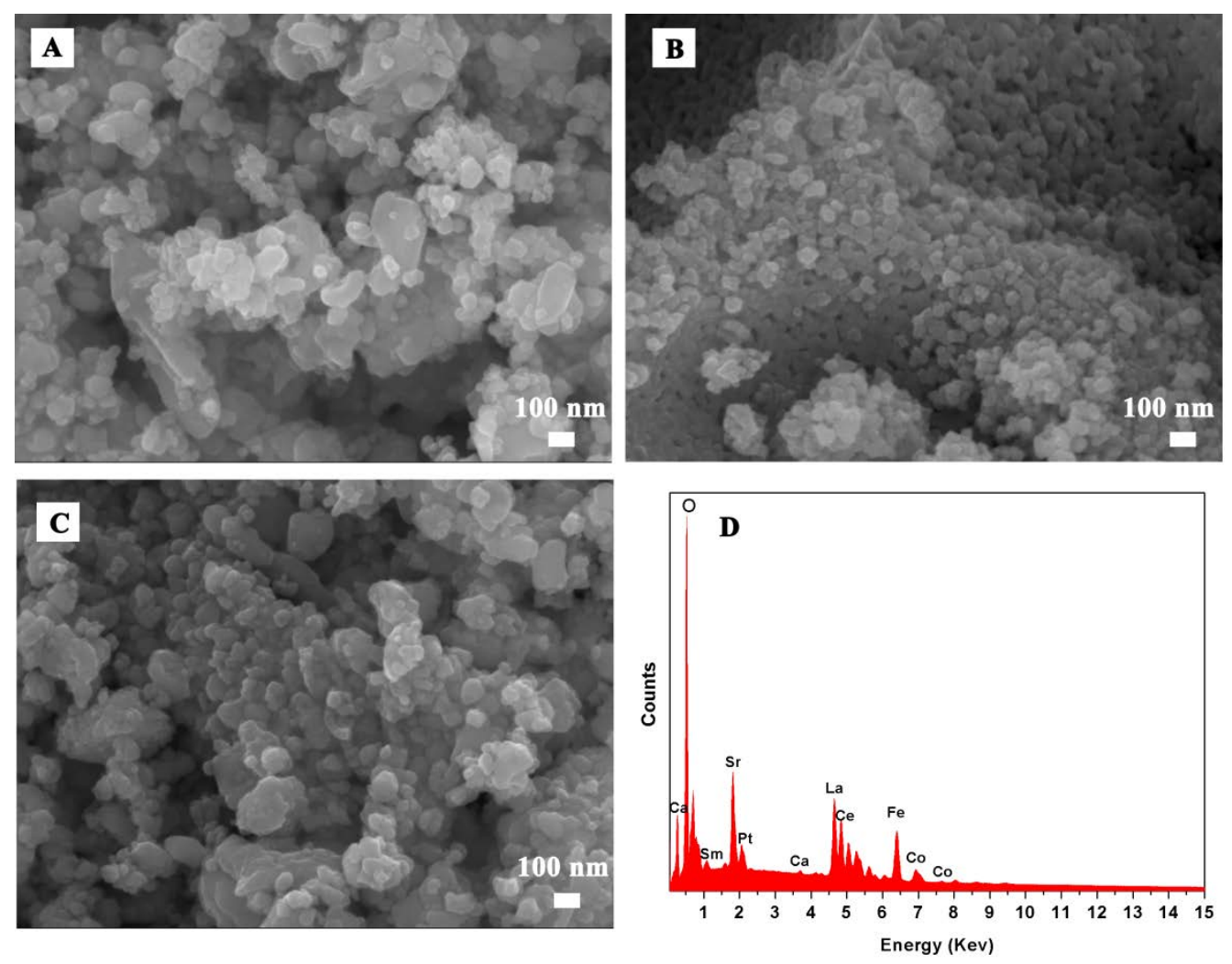

Figure 3. SEM images of LSCF (A), SCDC (x=0.16) (B) and 50LSCF-50SCDC composites (C)

0.6: 0.4: 0.2: 0.8 indicating the LSCF is stoichiometric, and the EDS data D was obtained from all of the area in Figure 3C. To gain further insight into the chemical composition of the particles, the elemental mapping was introduced to detect the LSCF- SCDC composite, as shown Figure 3s. Briefly, all the elements were uniformly distributed on the sample, which will be helpful for 
establishing continuous networks and charge transport paths for both ions and electrons.

Further details of nanostructure for the SCDC $(\mathrm{x}=0.16)$ samples were investigated by transmission electron microscopy (TEM) as shown in Figure 4A, the particle size of SCDC $(\mathrm{x}=0.16)$ is about $20 \mathrm{~nm}$, which agrees well with the result of SEM analysis. The microstructure under higher magnification, achieved by high-resolution TEM (HRTEM), is shown in Figure 4B, which reveals that the dominant lattice fringe is equal to the spacing of (111) planes in SCDC.
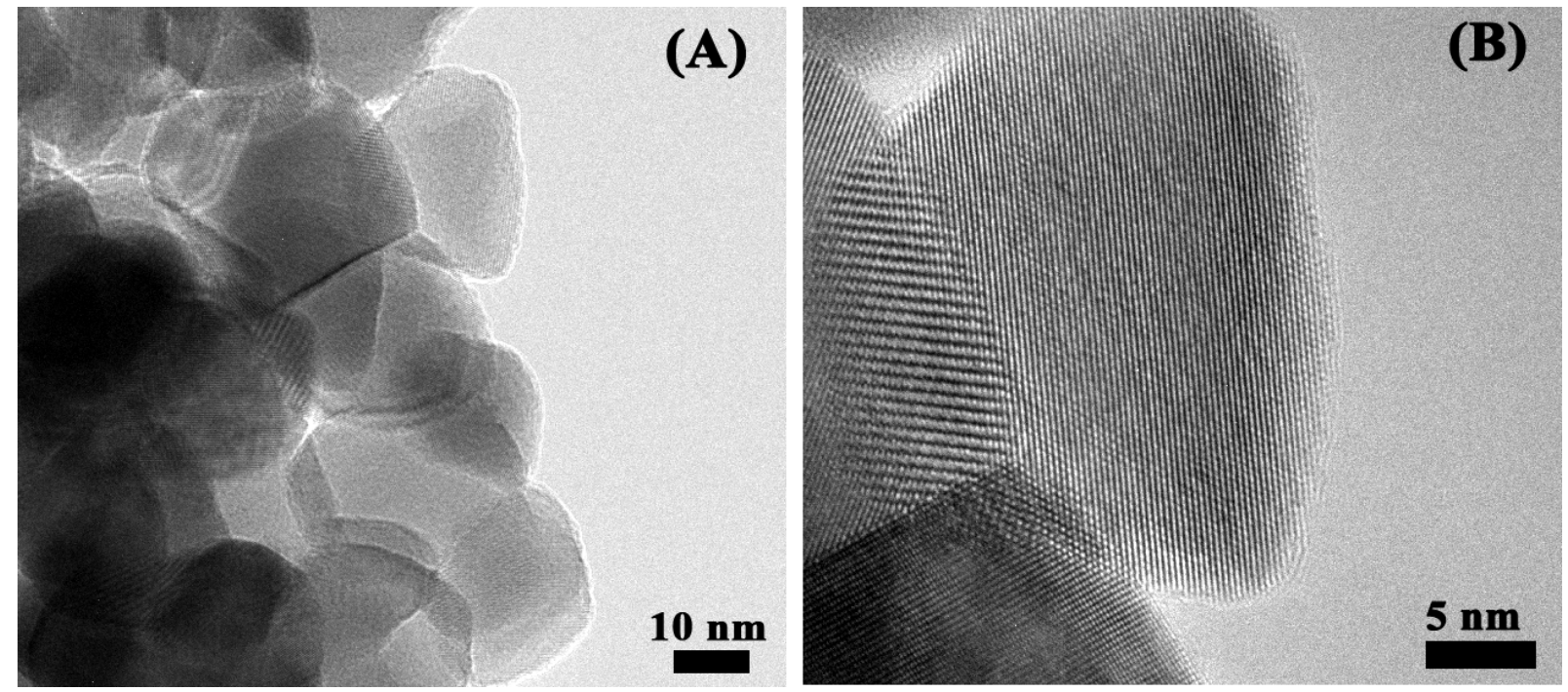

Figure 4. Individual SCDC( $\mathrm{x}=0.16)$ samples (A) TEM image (B) HRTEM image.

The electrochemical impedance spectrum (EIS) of Ag/LSCF-SCDC /Ag configuration was measured. Typical EIS measured in air atmosphere for various LSCF-SCDC samples are shown in Figure 5. The EIS results of LSCF-CDC and LSCF-SCDC1 samples exhibit a diffused spot in the Z'-axis, which may be due to the overwhelming electronic conductivity of LSCF compared to the ionic value of CDC and SCDC1 ${ }^{[21]}$. As reported, the electrical conductivity of LSCF was maintained at about $215.58 \mathrm{~S} \mathrm{~cm}^{-1}$ in the temperature range of $373-1023 \mathrm{~K}^{[22]}$. Thus, the LSCF 
electronic conduction dominates these composites including LSCF-CDC and LSCF-SCDC1. In addition, the EIS were expanded from the spot to a frequency responding semicircle as the content of Sm dopant increased, which may be induced by the increasing ionic conductivity of SCDC serials in competing with the LSCF electronic conductivity. The samples of LSCF mixed with SCDC2, SCDC3 and SCDC4 reveal a small intercept on the real axis of the semicircle, which implies that the electrode reactions are kinetically fast ${ }^{[12,23-25]}$, and also gives strong evidence that the mixed LSCF-SCDC homogeneous composites have high catalytic activity for $\mathrm{O}_{2}$ and good fuel cell performance, as seen from the below section of FC performance analyses. Moreover, the intersection of semicircle in the high frequency region and the associated real axis value corresponds to the ohmic resistance, which was contributed by both the oxygen ions and electrons in the air atmosphere, indicating the three samples have identical ohmic resistance. Moreover, in the low frequency region, another intersection of the semicircle with Z'-axis corresponded to grain boundary resistance. The EIS curves reflect that the grain boundary resistance of the cell increased with amount of Sm dopant. 


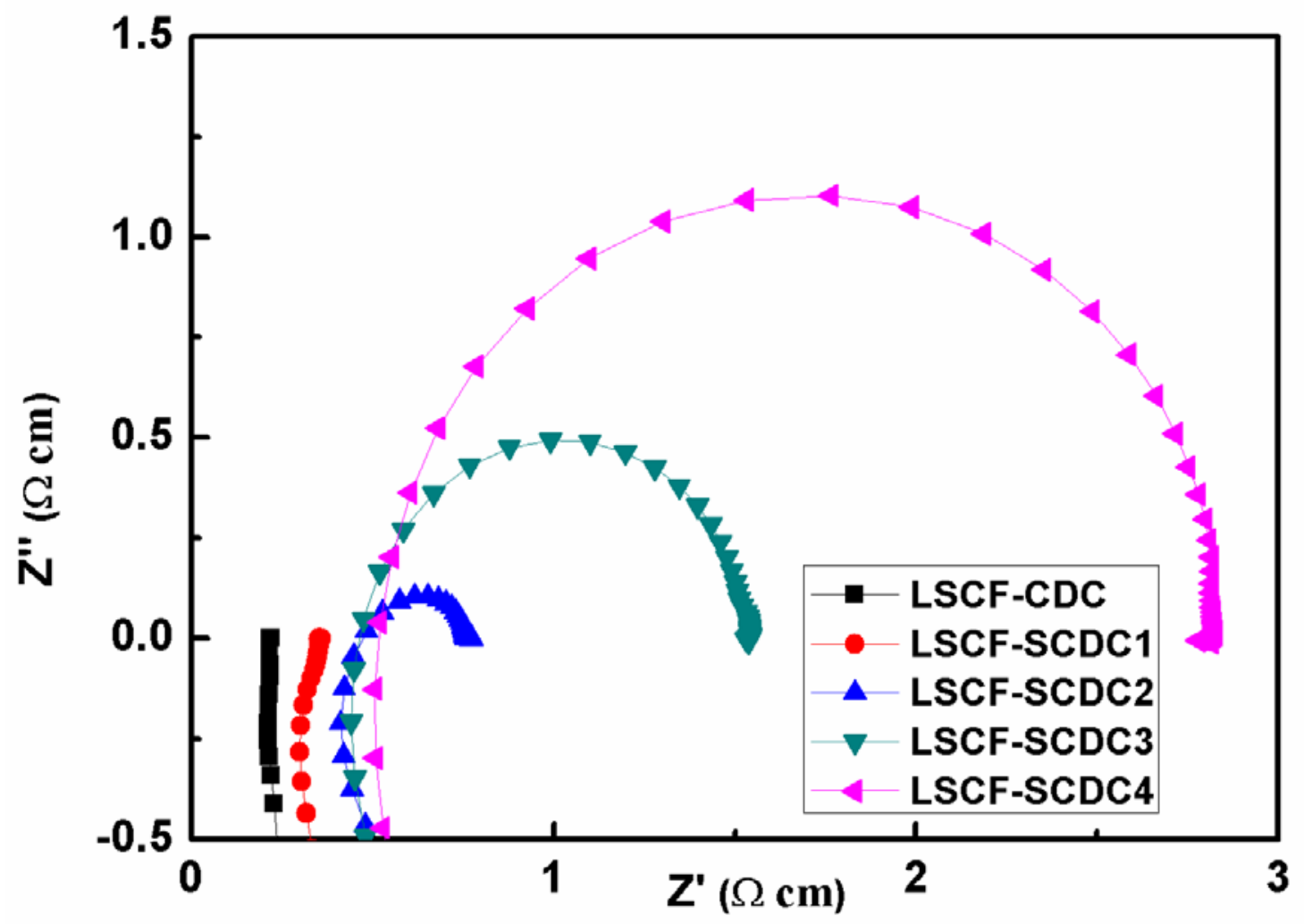

Figure 5. Typical EIS of the LSCF-SCDC ( $\mathrm{x}$ for $\mathrm{Sm}=0,0.05,0.09,0.16,0.24$ ) mixed layer with 1:1 weight ratio in air atmospheres at $550{ }^{\circ} \mathrm{C}$ using the configuration of Ag/LSCF-SCDC/Ag.

The Nyquist curves of cells with Ni-NCAL/LSCF-SCDC3/Ni-NCAL structure recorded at different temperatures are presented in Figure 6. An equivalent circuit mode of $\mathrm{R}_{\mathrm{s}} / \operatorname{Rct}\left(\mathrm{CPE}_{1}\right) / \mathrm{R}_{\mathrm{mt}}\left(\mathrm{CPE}_{2}\right)$ was used to fit the original data ${ }^{[26,27]}$. In this circuit, $\mathrm{R}_{\mathrm{s}}$ is the series resistance of the cells including the ionic transport resistance and electron migration resistance. $\mathrm{R}_{\mathrm{ct}}$ at high frequency zone corresponds to the interfacial charge-transfer resistance of the LSCFSCDC composites layer and NCAL interface. $\mathrm{C}_{1}$ is the chemical capacitance, and directly associated with ambipolar diffusion in LSCF-SCDC material, where the ambipolar diffusion coefficient is an aggregate one describing the flux of matter through the system as a whole. Especially for the semiconductor-ion conductor LSCF-SCDC, in which oxygen vacancies, hole 
and electrons are mobile, the ambipolar or chemical diffusion coefficient relates the flux of neutral oxygen atom to the gradient in the oxygen ${ }^{[28,29]}$. Thus, the absolute value of chemical capacitance depends on the properties and geometry of LSCF-SCDC composites, generally ranging from $10^{-3}$ to $10 \mathrm{~F} \mathrm{~cm}^{-2}$. In the low frequency range, $\mathrm{R}_{\mathrm{mt}}$ and $\mathrm{C}_{2}$ of $\mathrm{CPE}_{2}$ are related to the mass transport resistance and capacitance of the LSCF-SCDC and NiCo (Li) metal, which reduces from nickel-cobalt-based oxide at $\mathrm{H}_{2}$ atmosphere. In addition, the CPE is the constant phase element and represents a non-ideal capacitor. The impedance of the components can be expressed by the below formula:

$$
Z=\frac{1}{C_{i}(j w)^{n}}(1)
$$

Here the value of $n$ indicates the similarity of CPE to a true capacitor, when assuming $n=1, C P E$ can be deemed as an ideal capacitor. In the usual case $n$ is less than $1^{[30,31]}$. As shown by Figure 6A, the impedance spectra possess two overlapped arcs. The smaller depressed arc on the left is associated with a high frequency region and the larger arc on the right corresponds to the low frequency zone. The fitting impedance results using this equivalent circuit mode are listed in Table 2. The simulation is in agreement with the experimental data, see Figure 6A, indicating the validity of the employed equivalent circuit. From Table 2, the charge transfer resistance $\mathrm{R}_{\mathrm{ct}}$ between $500{ }^{\circ} \mathrm{C}$ and $600{ }^{\circ} \mathrm{C}$ are smaller than $0.04 \Omega \mathrm{cm}^{2}$, much less than the reported value of $0.748 \Omega \mathrm{cm}^{2}$ for $\mathrm{SDC}^{[32]}$. In addition, the $\mathrm{R}_{\mathrm{ct}}$ decreased during temperature increase which may attributes to the enhanced charge mobility. The mass transport resistance shows small values from $0.0390 \Omega \mathrm{cm}^{2}$ to $0.0546 \Omega \mathrm{cm}^{2}$ at $500-600{ }^{\circ} \mathrm{C}$, indicating an excellent contact between the NCAL and LSCF-SCDC semiconductor-ionic layer and fast kinetic process in FC environment. 


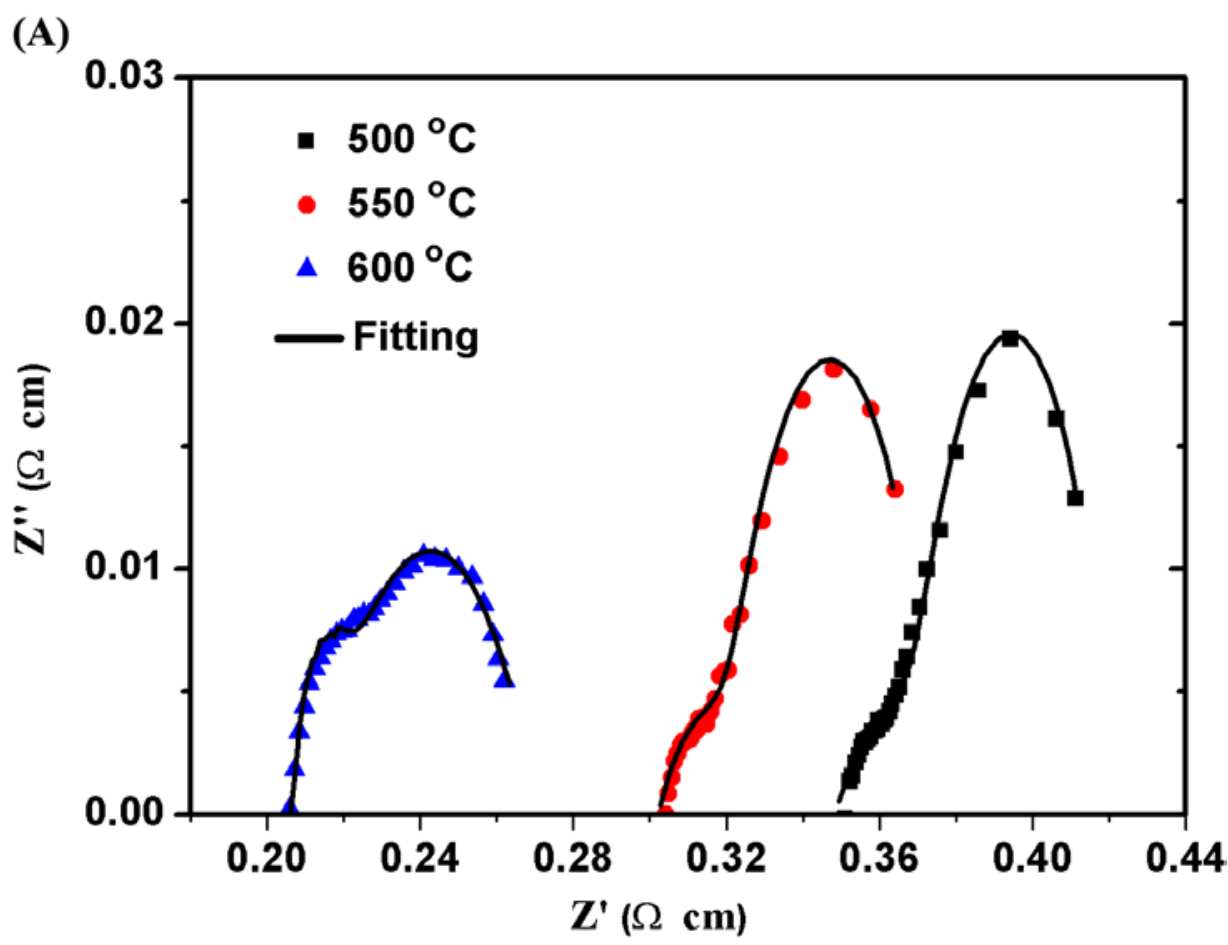

(B)

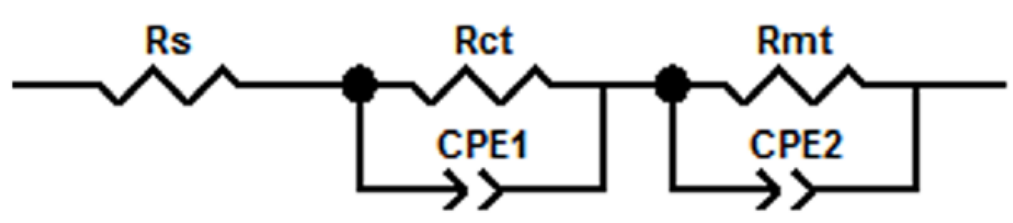

Figure 6. Nyquist curves of Ni-NCAL/LSCF-SCDC3/Ni-NCAL cells using $\mathrm{H}_{2}$ as fuel and air as oxidant at different temperature (A), in which the scatter dots are the original data, while the lines belong to the simulated result using the equivalent circuit (B) .

Table 2. The fitting results of impedance spectra using the $R_{s} / R_{1}\left(C P E_{1}\right) / R_{c t}\left(C P E_{2}\right)$ equivalent circuit. Resistance and capacitance are given in $\Omega \mathrm{cm}^{2}$ and $\mathrm{F} \mathrm{cm}^{-2}$.

\begin{tabular}{cccccccc}
\hline & $\mathrm{R}_{S}\left[\Omega \mathrm{cm}^{2}\right]$ & $\mathrm{R}_{\mathrm{ct}}\left[\Omega \mathrm{cm}^{2}\right]$ & $\mathrm{C}_{1}\left[\mathrm{~F} \mathrm{~cm}^{-2}\right]$ & $\mathrm{n}$ & $\mathrm{R}_{\mathrm{mt}}\left[\Omega \mathrm{cm}^{2}\right]$ & $\mathrm{C}_{2}\left[\mathrm{~F} \mathrm{~cm}^{-2}\right]$ & $\mathrm{n}$ \\
\hline $500^{\circ} \mathrm{C}$ & 0.348 & 0.0358 & $5.6 \mathrm{E} 10-2$ & 0.295 & 0.0390 & 8.864 & 0.893 \\
$550{ }^{\circ} \mathrm{C}$ & 0.302 & 0.0237 & $3.7 \mathrm{E} 10-2$ & 0.381 & 0.0483 & 7.476 & 0.788 \\
$600{ }^{\circ} \mathrm{C}$ & 0.206 & 0.0096 & $2.9 \mathrm{E} 10-2$ & 0.934 & 0.0546 & 2.542 & 0.473 \\
\hline
\end{tabular}


Figure 7 (a) shows the typical current density-voltage (I-V) and (current-power) I-P curves of cells assembled from Ni-NCAL/LSCF-SCDC/Ni-NCAL structure with different Sm contents at $550{ }^{\circ} \mathrm{C}$. It is obviously that the Sm and Ca co-doped ceria present better output performance than that of Ca single doped samples due to the higher ionic conductivity of SCDC samples. Interestingly, the maximum output power density initially increased with the contents of doped Sm, then decreased. The highest power density of $798 \mathrm{~mW} \mathrm{~cm}^{-2}$ (at $550{ }^{\circ} \mathrm{C}$ ) was obtained when $\mathrm{x}$ equals to 0.16. For $\underline{B y}$-_comparisons, the FCs using pure ionic SCDC membrane and the conventional SOFC device based on the SCDC electrolyte, reach $368 \mathrm{mWcm}^{-2}$ and $300 \mathrm{mWcm}^{-2}$ at $550{ }^{\circ} \mathrm{C}$, respectively, see Figure 7 (b). The results suggest a superior device performance for the semiconductor-ionic LSCF-SCDC membrane FC. Obviously, the interfaces between the ionic electrolyte/membrane and electrode (anode and cathode) in FC technologies (i.e. the gap blocks the charge carrier) can generate poor current outputs due to big polarization loss ${ }^{[33]}$. We further investigate the material electrical properties. The ionic conductivity can be derived from the slope of I-V characteristic and corresponds to the ionic sources, which contributed to the fuel cell performance ${ }^{[34,35]}$. Herein, we calculate the ionic conductivities of LSCF-SCDC serials, $0.173 \mathrm{~S}$ $\mathrm{cm}^{-1}, 0.184 \mathrm{~S} \mathrm{~cm}^{-1}, 0.237 \mathrm{~S} \mathrm{~cm}^{-1}, 0.299 \mathrm{~S} \mathrm{~cm}^{-1}$ and $0.209 \mathrm{~S} \mathrm{~cm}^{-1}$, respectively for various compositions at $550{ }^{\circ} \mathrm{C}$. The calculated pure SCDC conductivity is $0.112 \mathrm{~S} \mathrm{~cm}^{-1}$ at the same temperature. It can be found that the LSCF-SCDC3 exhibited the highest ionic conductivity, which results in the highest power output. An increase in the amount of Sm dopant in the CDC gives a rise to the replacement of tetravalent Ce ion with trivalent $\mathrm{Sm}$ ion, and more oxygen vacancies were introduced. The analysis can be confirmed by the EDS results, as listed in Table 1, where the $\delta$ value increases from 0.16 to 0.79 . Banerjee et al., report a maximum conductivity 
of $0.122 \mathrm{~S} \mathrm{~cm}^{-1}$ at $700{ }^{\circ} \mathrm{C}$ for the SCDC with a composition $\mathrm{Ce}_{0.80} \mathrm{Sm}_{0.05} \mathrm{Ca}_{0.15} \mathrm{O}_{2-\delta}{ }^{[18]}$. In our work, a higher ionic conductivity of SCDC in presence of the LSCF composite material was obtained. Except for the co-doping effect, the conduction through surface or interface mechanisms between the SCDC and LSCF could be also considered to facilitate higher conductivity than the pure SCDC ${ }^{[36]}$. At the interface area, a narrow charge region, the so-called space-charge region is thermodynamically necessary. The defect concentrations in the spacecharge region are much higher than that in the bulk, thus interface provides high conductivity pathways for ionic transportation and conduction. This interfacial effect is dominant in overall ionic transport, especially in nanocomposites, and can explain the greatly enhanced ionic conductivity of LSCF-SCDC composite compared to the pure SCDC ${ }^{[37-39]}$. 

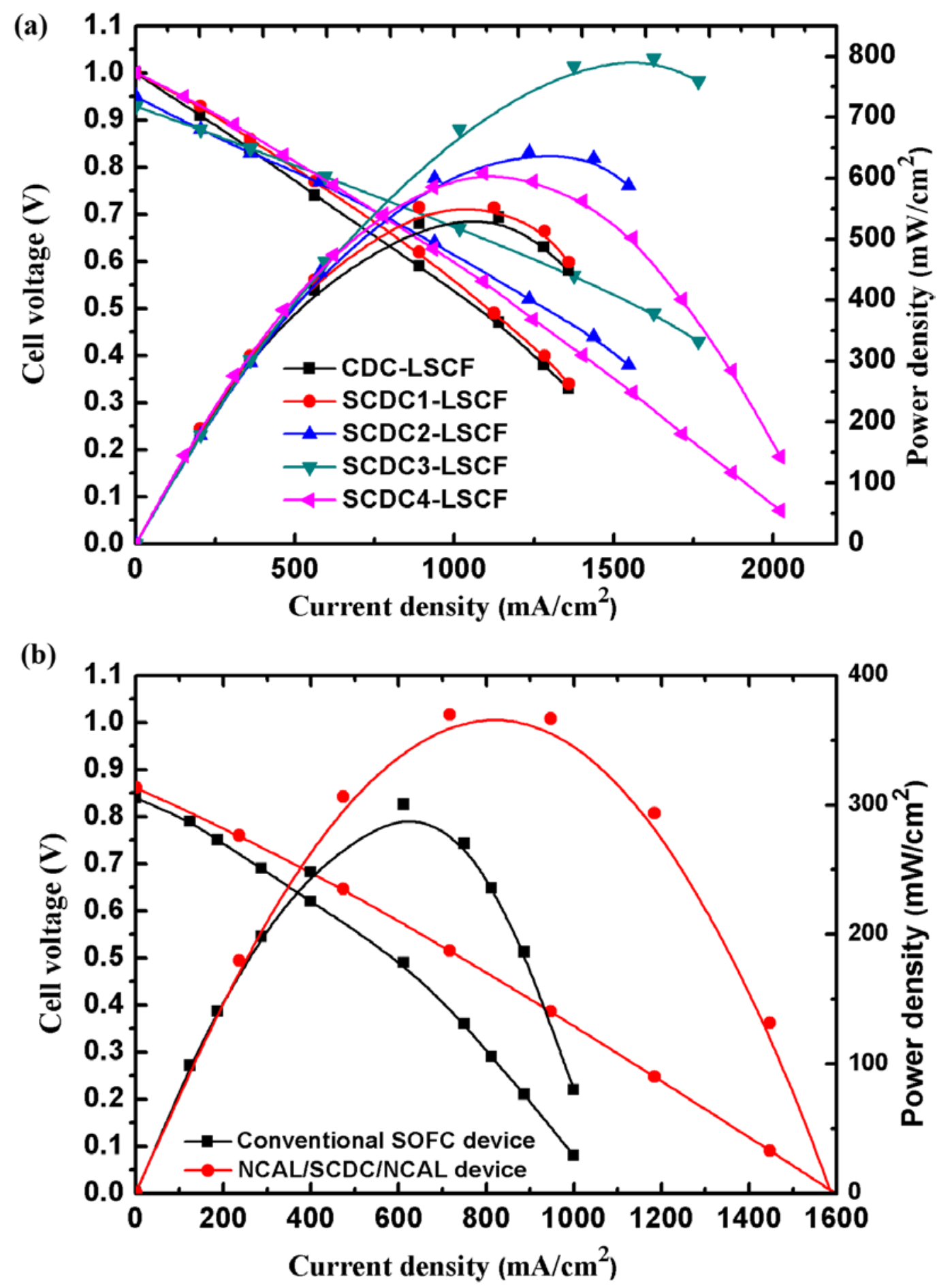

Figure 7. (a) Typical I-V and I-P characteristics for the LSCF-SCDC membrane FCs in various Sm dopants at $550{ }^{\circ} \mathrm{C}$. (b) Performances of conventional SOFC and FC using pure SCDC membrane devices at $550{ }^{\circ} \mathrm{C}$. (b)

We further investigated the influence of semiconductor-ionic composition towards the 
performance of FCs. Figure 8 presents the I-V and I-P curves of FCs made from semiconductorionic membrane with different LSCF to SCDC weight ratios at $550{ }^{\circ} \mathrm{C}$. A significant dependence of the OCV and power output on LSCF composition can be observed. As the weight ratio of LSCF increases to $45 \%$, the OCV displayed a value of $1.1 \mathrm{~V}$, and the output increased to 539 $\mathrm{mW} \mathrm{cm}^{-2}$. Further increase content of the LSCF causes the OCV decrease to $0.95 \mathrm{~V}$, but the power output reached a maximum of $796 \mathrm{~mW} \mathrm{~cm}^{-2}$. When $55 \mathrm{wt} \%$ of LSCF is introduced, the OCV did not decrease, but the power density decreased to $440 \mathrm{~mW} \mathrm{~cm}^{-2}$.

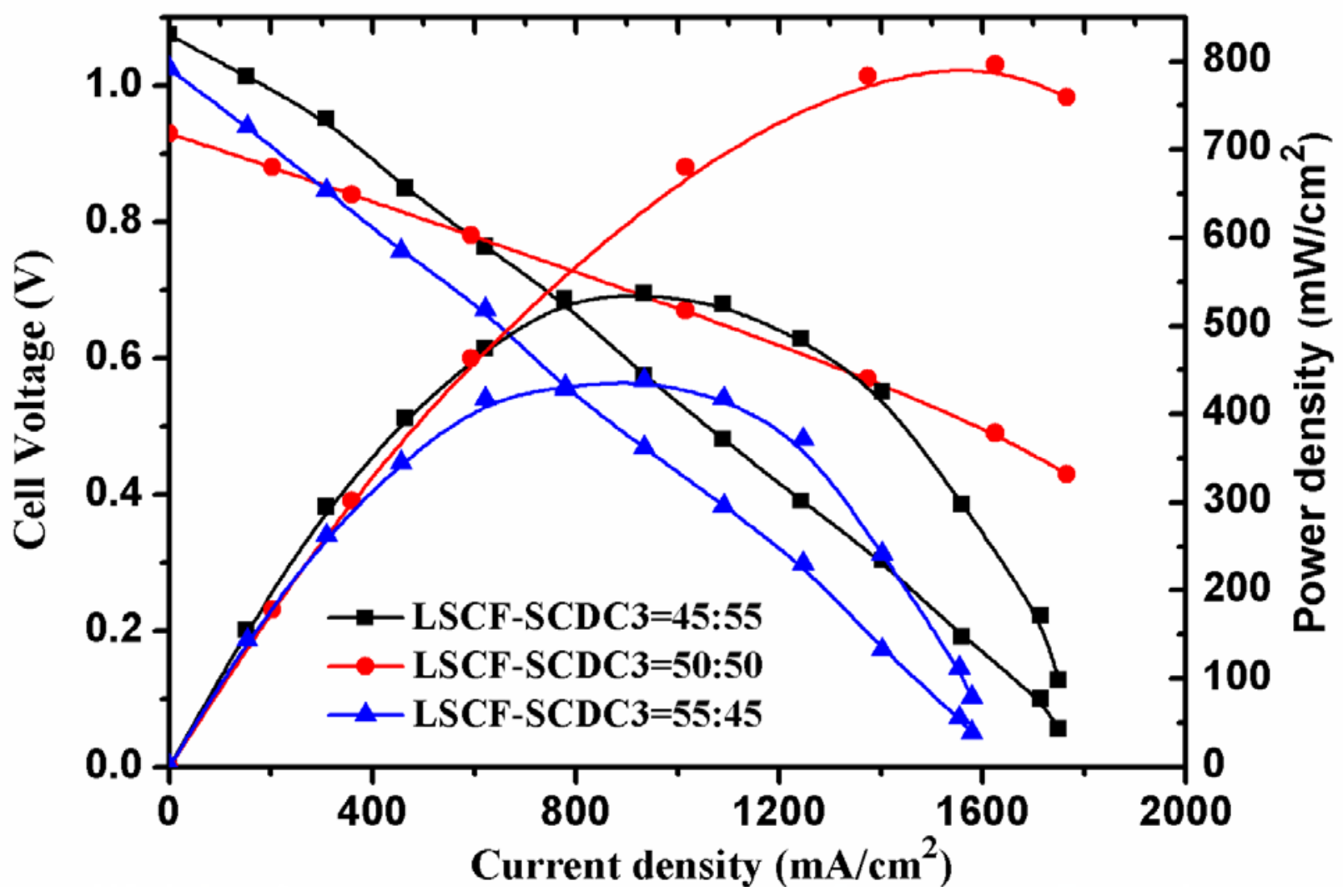

Figure 8. Comparison of I-V and I-P characteristics for semiconductor-ion membrane FCs with various LSCF-SCDC weight ratios at $550{ }^{\circ} \mathrm{C}$.

We found that the maximum power output can be optimized by balancing the electronic and ionic conductivity of the LSCF-SCDC. It is necessary to further investigate the electronic and ionic conductivities of the LSCF-SCDC composite. Two different approaches can be used. The 
ionic conductivity was derived from the slope of the fuel cell's I-V curves which directly corresponds to the ion flows in the FC ${ }^{[34,35]}$. The EIS analysis is commonly used to measure the total conductivities including ionic and electronic contributions. The LSCF-SCDC materials contain both electronic and ionic contributions, wherein the electronic conduction brings dual impacts on the performance of the fuel cells simultaneously. With a sufficient electronic contribution, the three phase boundary (TPB) of the LSCF-SCDC layer is significantly extended, and the electrode polarization is decreased accordingly. However, the excess electronic conductivity will induce short-circuit through the functional region and results in the decrease of OCV and power output ${ }^{[39,40]}$. Therefore, it is necessary to achieve the optimum electronic conductivity by adjusting the weight ratio of SCDC and LSCF. The total conductivity of the LSCF-SCDC3 (1:1) composite, including electronic and ionic conductivity, can be deduced from the $\mathrm{R}_{\mathrm{S}}$ of EIS measurement. It displays a value of $0.608 \mathrm{~S} \mathrm{~cm}^{-1}$. On the other hand, the ionic conductivity, $0.299 \mathrm{~S} \mathrm{~cm}^{-1}$, can be calculated from the slope of I-V curve in Figure 8 for the LSCF-SCDC3 FC. The total conductivity subtracted by the ionic one to get the electronic conductivity of $0.309 \mathrm{~S} \mathrm{~cm}^{-1}$. Therefore, the LSCF-SCDC3 (1:1) composite almost has the same ionic conductivity and electronic conductivity, and a balance has been well reached between ionic and electronic conductivities.

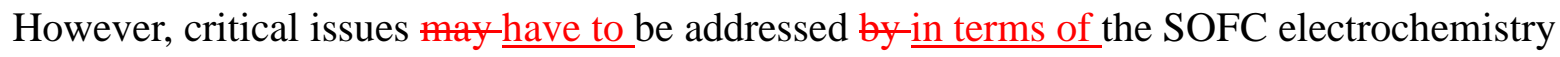
because the LSCF-SCDC is a type of the-mixed ionic and electronic conductor (MIEC), which can never replace the electrolyte to be used as the fuel cell membrane, otherwise, the short circuiting problem will cause serious device OCV and power output losses. Nevertheless, the true empirical observationssituations in the LSCF-SCDC devices does not agree with the FC 
electrochemistry and the MIEC behaviors. This is mainly-because i)the LSCF-SCDC does not cause any OCV loss in a wide composition range compared to the pure SCDC electrolyte device, which was fabricated using conventional FC configuration as shown in the Figure. 1s(c) show ${ }_{2}$ with an OCV of $0.85 \mathrm{~V}$. The resulting lower OCV can be attributed to the intrinsic electron conduction $\theta$ fof the_ceria-based electrolyte, which is induced during hydrogen reduction process ${ }^{[41-43]}$. While LSCF electronic conductor increased from 0 up to 55\%, the OCV increased from pure ionic conductor SCDC electrolyte device $0.85 \mathrm{~V}$ up to $1.07 \mathrm{~V}$ at $45 \%$; to $1.03 \mathrm{~V}$ at $55 \%$; ii) increasing the weight ratio of LSCF does not cause the power loss, but increased significantly from pure SCDC at $300-367 \mathrm{~mW} \mathrm{~cm}^{-2}$ up to $796 \mathrm{~mW} \mathrm{~cm}^{-2}$ at $50 \%$.

It is well-known that once the MIEC acted as an electrolyte membrane, which-it will cause significant losses in both voltage and power of the assembled device ${ }^{[41-43] .}$ However, by comparing the ionic SCDC with the LSCF-SCDC membrane, it can be found that the incorporation of electronic conductor into the membrane did not cause any loss for OCV or power output, instead giving rise to whereas resulted in-much better improved performances. The above indicates a different phenomenon significantly distinguished from the MIEC, and the LSCF-SCDC may be defined as a new type of functional semiconductor-ionic material which has not been reported so far, to the best of our the authors' knowledge. As shown in Figure 3C, the homogeneous LSCF-SCDC mixture layer is built upon nanocomposite with a typical morphology of semiconductor material adhered to the surface of ion conducting material, both phases form percolating paths for ion and electron transport. The composite in such microstructure architecture serves as the fuel cell membrane. According to the MIEC theory ${ }^{[44]}$, the short circuiting problem would occur since the electronic phase is constructed continuously 
throughout the device. On the contrary, the FCs based on LSCF-SCDC membrane achieves even higher OCVs than that of the FC using the SCDC electrolyte. To understand this outcome, semiconducting and energy band theories are introduced ${ }^{[45]}$. The valence band, the conduction band and band gap were obtained from the ultraviolet photoelectron spectroscopy (UPS) measurement and diffused reflectance spectra on NCAL and LSCF, the analyses are provided in the supplementary information Figure 4s. Figure 9 shows establish energy level diagram from the analysis. The energy band alignment between the LSCF and NCAL can block the electron transport but allow holes to pass. This well-aligned band level enables the creation of a new mechanism to prevent the semiconductor-ionic membrane device from short-circuiting and promote charge flows, and the ion transport and charge transfer more directly rather than the use of the electrolyte separator in the FC. On the other hand, the NCAL can be reduced at the anode side, to form Ni-Co metal surface thus a Schottky junction may be established between the metal layer and semiconductor material LSCF. Such a Schottky junction can also block electrons crossing over the metal/semiconductor interface to the opposite side ${ }^{[46]}$. Differing from the conventional FCs, the working principle here is unique in combining semiconductor physics and electrochemistry. 


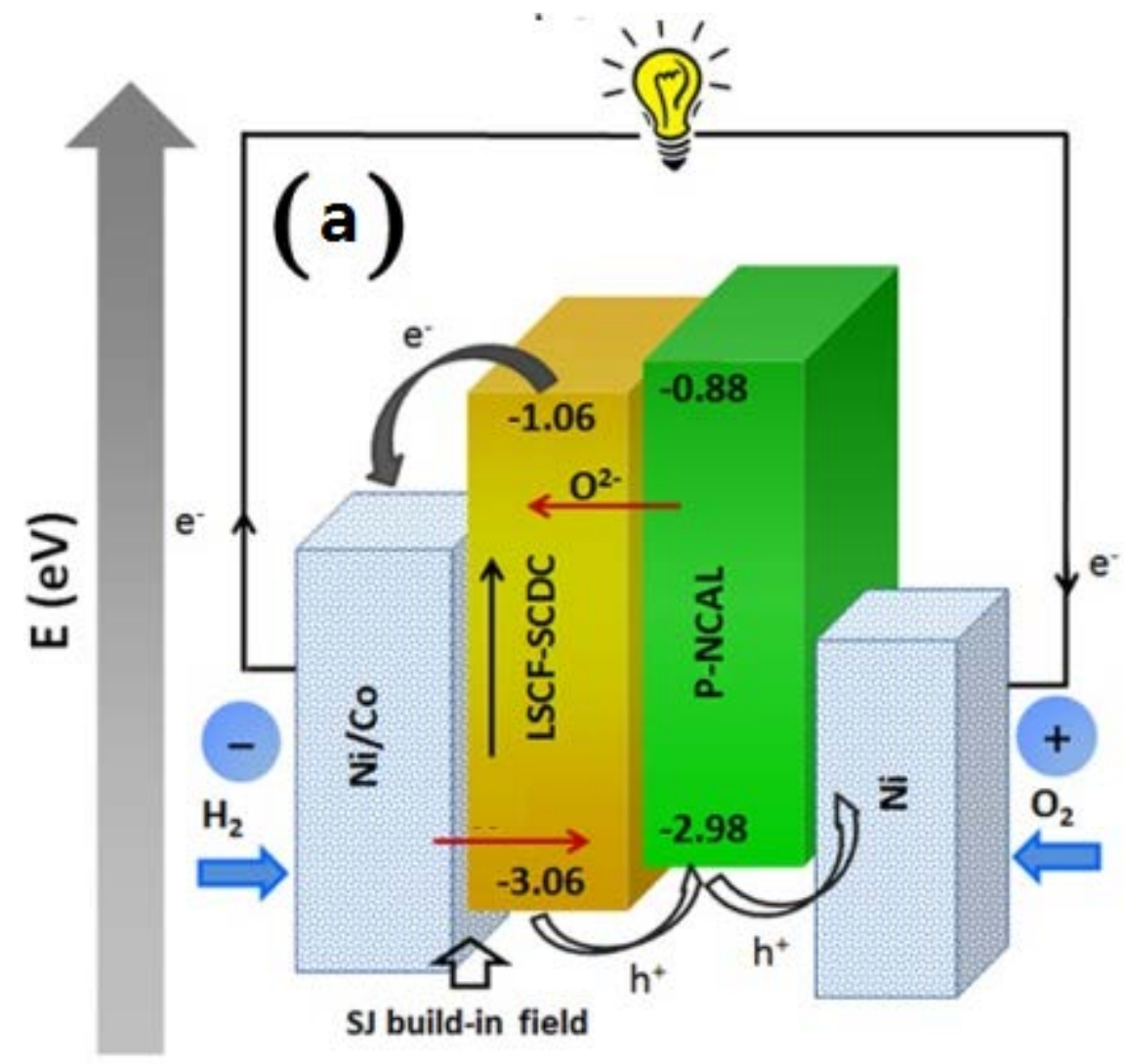

Figure 9. Schematic energy level diagrams and valence bands of materials with an in-situ formed Schottky-junction.

In combination with the mechanisms for Schottky junction and energy band alignment, the electron and hole flows are directed and controlled so that internal short-circuit is eircumventedmilitated. At the same time, the LSCF-SCDC layer can simultaneously transport $\mathrm{O}^{2-}$ effectively in direct contact with electrodes, avoiding the electrode/electrolyte interfaces polarization losses thus giving rise to a significant performance enhancement. The chemical potential and gas concentration differences, built by means of supplying $\mathrm{H}_{2}$ and air, are the principal driving force for ion transportation. The fuel conversion process is thus similar to FCs, i.e. cathode oxygen reduction reaction (ORR) at the air contact side and hydrogen oxidation 
reaction (HOR) at the $\mathrm{H}_{2}$ supply side.

In the $\mathrm{O}^{2-}$ conducting case, the ORR and HOR can be expressed as:

$$
\begin{aligned}
& \frac{1}{2} \mathrm{O}_{2}+2 e^{-} \rightarrow \mathrm{O}^{2-} \text { (At air supply side) } \\
& \mathrm{H}_{2}+\mathrm{O}^{2-} \rightarrow \mathrm{H}_{2} \mathrm{O}+2 e^{-} \text {(At } \mathrm{H}_{2} \text { supply side) }
\end{aligned}
$$

The overall reaction is: $\mathrm{H}_{2}+\frac{1}{2} \mathrm{O}_{2} \rightarrow \mathrm{H}_{2} \mathrm{O}$.

A further analysis of the Schottky junction shows a very compatible and promoting anode process as illustrated in Figure 10, and also presents more advanced technology over conventional SOFCs. In a common SOFC process, the anode nickel oxide is reduced to metal type to produce the catalyst function for the anode reaction, i.e. hydrogen oxidation reaction (HOR). This process is actually a metallization process requiring the participation of the Schottky metal and junction while the NCAL is reduced to NiCo (Li) metal in-situ anode process. Once the Schottky junction is formed between the metal and p-semiconductor LSCF, the built-in field directs from the metal to LSCF (P type), itwhich can prevent the electrons passing through the interface between metal/LSCF-SCDC and hence establishing establishes the device OCV. Moreover, the built-in filed field can actually promote the $\mathrm{O}^{2-}$ across over the junction, i.e. at the anode zone, as shown in Figure 10 (a). For the ionic SCDC membrane devices, though the same anode reaction process occurring in the FCs, it does not involve the semiconductor junction effect. Moreover, $\mathrm{O}^{2-}$ from the SCDC electrolyte membrane has to overcome the interface between the SCDC and the electrodes (anode and cathode) which are limiting factor to numbers of $\mathrm{O}^{2-}$ ions crossing the interface to complete the FC reactions, thus causing major power losses [16]. Figure 10 illustrates a comparison for the anode process between different devices and mechanisms for using the semiconductor-ion, LSCF-SCDC and ionic SCDC membranes, 
respectively.
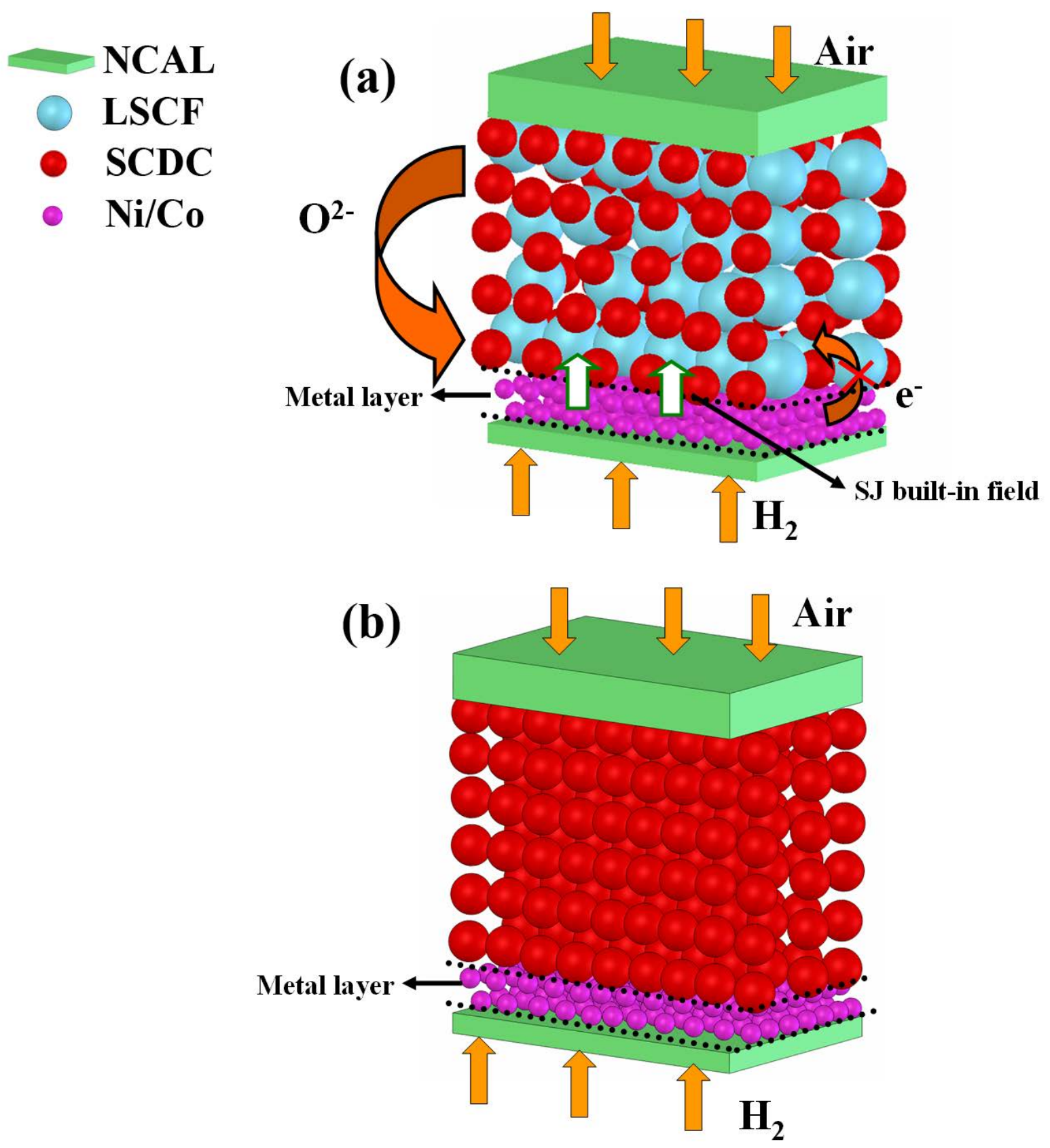

Figure 10. a. anode process with the semiconductor-ion LSCF-SCDC membrane, where a Schottky junction (built in field as indicated by arrows as driving force) promote the $\mathrm{O}^{2-}$ crossing over to complete the FC reaction; b. In the ionic SCDC membrane case there is no such driving force, so numbers of $\mathrm{O}^{2-}$ crossing the anode/electrolyte interface are limited.

In conclusion, the LSCF-SCDC semiconductor-ionic materials have displayed higher ionic 
conductivities than that of pure SCDC. In addition, the matched electronic conductivity can be maintained to deliver high power outputs. Such a novel device using the semiconducting-ionic LSCF-SCDC membrane obtained 2-3 times power output enhancement of those using the pure SCDC electrolyte/membrane, i.e. the eommon-present standard of FC devices. The working principle can be explained as the physical semiconductor energy band alignment incorporating with-the Schottky junction. These may novel semiconductor-ionic device, indicating a significant new scientific principle distinct from, and advantageous over $_{2}$ the FC. The concept of combining semiconductor physics and ionic electrochemical FC process displays a great potential for a new-generation energy conversion process to be explored and expanded with applicability in wide areas.

\section{Experimental Section}

\section{The Materials synthesis:}

$\mathrm{Sm} / \mathrm{Ca}$ co-doped $\mathrm{CeO}_{2}$ was synthesized by a two-step wet chemical method.

\section{Step 1. The CDC power synthesis.}

The $\mathrm{Ca}_{0.04} \mathrm{Ce}_{0.96} \mathrm{O}_{2-\delta}$ powder was synthesized by a co-precipitation method. Stoichimetric amount of $\mathrm{Ce}\left(\mathrm{NO}_{3}\right)_{3} \cdot 6 \mathrm{H}_{2} \mathrm{O}$ and $\mathrm{Ca}\left(\mathrm{NO}_{3}\right)_{2}$ were mixed and dissolved in deionized water to form a $0.5 \mathrm{M}$ solution. The solution was stirred at $80{ }^{\circ} \mathrm{C}$ for 30 minutes. The $\mathrm{Na}_{2} \mathrm{CO}_{3}$, used as a precipitating agent, was added into the mixed solution, after vigorous stirring to form a white precipitate. The precipitate was then filtrated and dried in an oven at $120{ }^{\circ} \mathrm{C}$ for $8-10 \mathrm{~h}$. Finally, the CDC precursor was calcined in a furnace at $800{ }^{\circ} \mathrm{C}$ for $4 \mathrm{~h}$. The resulting material was ground completely to obtain homogeneous CDC powders.

\section{Step 2. Sm doped CDC power preparation}


For the synthesis of Sm and Ca co-doped $\mathrm{CeO}_{2}$, various amounts of $\mathrm{Sm}\left(\mathrm{NO}_{3}\right)_{2}$ were added to the as prepared $\mathrm{Ca}_{0.04} \mathrm{Ce}_{0.96} \mathrm{O}_{2-x}$ powder and mixed with citric acid. Then, de-ionized water (10 ml) was added and the solution was stirred for 5 minutes to give a uniform mixture. The mixture suspension was sintered and dried at $80^{\circ} \mathrm{C}$ in air. Then the precursor was calcined at $800{ }^{\circ} \mathrm{C}$ for 2 $\mathrm{h}$ in a furnace. The resulting powder is a yellowish and foamy. Finally, complete grind was conducted to obtain homogeneous Sm and Ca co-doped $\mathrm{CeO}_{2}$ powders.

$\mathrm{La}_{0.6} \mathrm{Sr}_{0.4} \mathrm{Co}_{0.2} \mathrm{Fe}_{0.8} \mathrm{O}_{3-\delta}$ (LSCF) was purchased from Sigma Aldrich, USA, and the $\mathrm{Ni}_{0.8} \mathrm{Co}_{0.15} \mathrm{Al}_{0.05} \mathrm{Li}$-oxide (NCAL) was purchased from Tianjin Baomo Joint Hi-Tech venture, China.

\section{The fuel cell fabrication.}

Three kinds of FCs with different configurations was fabricated: (i) LSCF to SCDC in different mass ratios of 45:55, 50:50, and 55:45 were mixed to forming a homogenous layer, which sandwiched by two pieces of Ni foam pasted by NCAL, and then the three-layer pressed uniaxially under a load of 200-300 MPa into one tablet, the configuration illustrations was presented in Figure 1s (a) (ii) pure SCDC composites was sandwiched by two thin layers of NCAL pasted on Ni foam, then pressed using a 200-300 MPa loading into a pellet, as the Figure 1s (b) shown (iii) We constructed a device based on fuel cell technology as well with SCDC as the electrolyte, LSCF as the cathode and NCAL as anode for comparison. Both anode and cathode were prepared by mixing with SCDC electrolyte at a volume ratio of 1:1 in order to maximize the area of triple phase boundary. Ni-foam/anode/SCDC electrolyte/cathode/Ag is an example of such FC device shown in Figure 1s (c).

All devices after being mounted into the testing setup were examined using an in-situ pre- 
heat-treatment process at $600{ }^{\circ} \mathrm{C}$ for 1 hour; then temperature was lowered down to $550{ }^{\circ} \mathrm{C}$ for measurements. The resulting cell size is $13 \mathrm{~mm}$ in diameter and $1.5 \mathrm{~mm}$ in thickness with an active area of $0.64 \mathrm{~cm}^{2}$.

\section{Characterization and conductivity test}

The crystal structure of SCDC with different Sm dopant contents were analyzed by a Bruker D8 X-ray diffractometer (XRD, Germany, Bruker Corporation) using $\mathrm{Cu} K \alpha(\lambda=1.54060 \AA)$ as the source. The morphologies of samples were investigated by a JSM7100F field emission scanning electron microscope (FESEM, Japan). To further investigate the detailed microstructure of the particle, transmission electron microscopy (TEM) and high-resolution TEM (HRTEM) were performed using a JEOL JEM-2100F.

The characterization of fuel cell was performed using a computerized instrument (IT8511+, Ed, electronics co., LTD). Hydrogen was used as the fuel supplier at a flow rate of 80-120 ml $\min ^{-1}$, and air used as the oxidant at $150 \mathrm{ml} \mathrm{min}^{-1}$ under 1 atm pressure.

Electrochemical impedance spectrum (EIS) analysis was conducted using an electrochemical workstation (CHI-660D) under the open circuit voltage with a $10 \mathrm{mV}$ AC signal over the frequency range of $0.1-10^{5} \mathrm{~Hz}$ at different temperatures.

\section{Acknowledgment}

Financial support are from the National Natural Science Foundation of China (Grant 51402093, 51202213, Grant 51072049), China Postdoctoral Science Foundation (Grant 2013M530889), the Swedish Research Council (VR, Contract No. 621-2011-4983) and the EC

FP7 TriSOFC project (Contract No.303454). The joint technical development financed by 
Nanjing YuanNan Nano-Tech. Ltd is also acknowledged.

\section{References}

[1] W. R. Grove, Phil. Mag. Ser. 1839, 314, 127.

[2] B. C. H. Steele, J. Mater. Sci. 2001, 36, 1053.

[3] B. C. H. Steele \& A. Heinzel, Nature 2001, 414, 345.

[4] R. W. James, K. Worawarit, M. Roberto, H. Y. Chen, M. H. Jon, J. M. Dean, T. Katsuyo, W. V. Peter, B. A. Stuart, A. B. Scott. Nat. Mater. 2006, 5, 541.

[5] M. H. Sossina, A. B. Dane, R. I. C. Calum, B. M. Rvan, Nature 2001, 410, 910.

[6] T. Hibino, A. Hashimoto, T. Inoue, J. I. Tokuno, S. I. Yoshida, M. Sano, Science 2000, 288, 2031.

[7] Y. Wang, K. S. Chen, J. Mishler, S. C. Cho, X. C. Adroher , J. Power Sources 2011, 88, 981.

[8] G. F. McLean, T. Niet, S. P. Richard, N. Djilali, Int. J. Hydrogen Energy 2002, 27, 507.

[9] P. Stonehart, J. Appl. Electrochem. 1992, 22, 995.

[10] S. C. Singhal, Solid State Ionic 2000, 135, 305.

[11] A. A. David, I. S. Sergei, V. S. Natalia, A. A. Igor, J. Börje. Optimization of ionic conductivity in doped ceria. PNAS. 2006, 103, 3518.

[12] B. Zhu, R. Raza, G. Abbas, M. Singh, Adv. Funct Mater. 2011, 21, 2465.

[13] B. Zhu, R. Raza, H. Y. Qin, Q. H. Liu, L. D. Fan, Energy Environ. Sci. 2011, 4, 2986.

[14] X. Dong, L. Tian, J. Li, Y. C. Zhao, Y. Tian, Y. D. Li, J. Power Sources 2014, 249, 270.

[15] H. Q. Hu, Q. Z. Lin, Z. G. Zhu, B. Zhu, X. R. Liu, J. Power Sources 2014, 248, 577.

[16] C. W. Sun, R. Hui, J. Roller, J. Solid State Electrochem. 2010, 14, 1125.

[17] M. Mogensen, N. M. Sammes, G. A. Tompsett, Solid State Ionics 2000, 129, 63. 
[18] B. S. Banerjee, P. S. Devi, D. Topwal, S. Mandal, K. Menon, Adv. Funct. Mater. 2007, 17, 2847.

[19] H. T. Gu, H. Chen, L. Gao, Y. F. Zheng, X. F. Zhu, L. C. Guo, Int. J. Hydrogen Energy 2008, 33, 4681.

[20] F. Y. Wang, S. Y. Chen, S. Cheng, Electrochem. Commun. 2004, 6, 743.

[21] Y. J. Xia, X. J. Liu, Y. J. Bai, H. P. Li, X. L. Deng, X. D. Niu, X. J. Wu, D. F. Zhou, M. F. Lv, Z. C. Wang, J. Meng. RSC Adv. 2012, 2, 3828.

[22] A. Jun, S. Y. Yoo, O. H. Gwon, J. Y. Shin, G. Kim, Electrochim. Acta 2013, 89, 372.

[23] B. Zhu, R. Raza, H. Y. Qin, L. D. Fan, J. Power Sources 2011, 196, 6362.

[24] B. Zhu, Y. Ma, X. D. Wang, R. Raza, H. Y. Qin, L. D. Fan, Electrochem. Commun. 2011, 13, 225.

[25] B. Zhu, H. Y. Qin, R. Raza, Q. H. Liu, L. D. Fan, J. Patakangas, P. Lund, Int. J. Hydrogen Energy 2011, 36, 8536.

[26] X. Q. Yan, M. Hou, L. Y. Sun, D. Liang, Q. Shen, H. F. Xu, P. W. Ming, B. L. Yi, Int. J. Hydrogen Energy 2007, 32, 4358-4364.

[27] H. Q. Hu, Q. Z. Lin, A. Muhammad, B. Zhu, J. Power Sources 2015, 286, 388.

[28] W. Lai, S. M. Haile, J. Am. Ceram. Soc. 2005, 88, 2979.

[29] E. Fabbri, L. Bi, D. Pergolesi, E. Traversa, Enrgy Environ. Sci. 2011, 4, 4984.

[30] B. Hirschorn, M. E. Orazem, B. Tribollet, V. Vivier, I. Frateur, M. Musiani, Electrochim. Acta 2010, 55, 6218.

[31] J. B. Jorcin, M. E. Orazem, N. Pebere, B. Tribollet Electrochim. Acta 2006, 51, 1473.

[32] Z. Gao, R. Raza, B. Zhu, Z. Q. Mao, J. Nanosci. Nanotechno. 2011, 11, 5413. 
[33] J. R. Wilson, W. Kobsiriphat, R. Mendoza, H. Y. Chen., J. M. Hiller, Miller, D. J. Miller, K. Thornton, P. W. Voorhees, S. B. Adler, S. S. Barnett, Nat. Mat. 2006, 5, 541.

[34] B. Zhu, Electrochem. Commun. 1999, 1, 242.

[35] L. D. Fan, C. Y. Wang, M. M. Chen, J. Di, J. M. Zheng, B. Zhu, Int. J. Hydrogen Energy 2011, 36, 9987.

[36] G. L. Gregori, M. Shirpour, J. Maier, Adv. Funct. Mater. 2013, 23, 5861.

[37] J. Maier, Nat. Mater. 2005, 4, 805.

[38] Y. Ma, M. Singh, X. D. Wang, F. Yang, Q. A. Huang, B. Zhu, Int. J. Hydrogen Energy 2014, 39, 17460.

[39] X. Dong, L. Tian, J. Li, Y. C. Zhao, Y. Tian, Y. D. Li, J. Power Sources 2014, 249, 270.

[40] H. Q. Hu, Q. Z. Lin, A. Muhammad, B. Zhu, J. Power Sources 2015, 286, 388.

[41] A. Tschöpe, Solid State Ionics 2001, 129, 3.

[42] K. Eguchi, T. Setoguchi, T. Inoue, H. Arai, Solid State Ionics 1992, 52, 165.

[43] S. L. Shen, Y. P. Yang, L. J. Guo, H. T. Liu, J. Power Sources 2014, 256, 43.

[44] I. Riess, M. Gödickemeier, L. J. Gauckler, Solid State Ionics 1996, 90, 91.

[45] K. Singh, J. Nowotny, V. Thangadurai, Chem. Soc. Rev. 2013, 42, 1961.

[46] B. Zhu, P. D. Lund, R. Raza, Y. Ma, L. D. Fan, M. Afzal, J. Patakangas, Y. J. He, Y. F. Zhao, W. Y. Tan, Q. A. Huang, J. Zhang, H. Wang, Adv. Energy Mater. 2015, 5, 1401895. 